\title{
Trace element analysis of fly ash samples by EDXRF technique
}

\author{
T R Rautray ${ }^{1 *}$, B Behera ${ }^{1}$, T Badapanda $^{1}$, V Vijayan $^{2}$ and S Panigrahi ${ }^{1}$ \\ ${ }^{1}$ Department of Physics, National Institute of Technology, Rourkela-769 008, Orissa, India \\ ${ }^{2}$ Department of Physics, Valliammai Engineering College, SRM Nagar, Chennai-603 203, Tamil Nadu, India \\ E-mail : tapash77@hotmail.com
}

\begin{abstract}
Trace element analysis of some fly ash samples and soil samples have been carried out by Energy Dispersive X-Ray Fluorescence technique. Fourteen elements namely K, Ca, Ti, V, Cr, Mn, Fe, Co, Cu, Zn, $\mathrm{Se}, \mathrm{Rb}, \mathrm{Sr}$ and $\mathrm{Pb}$ have been quantified in the fly ash samples by this technique. It was found that there is no huge concentration difference between the fly ash and soil samples as a result of which fly ash can be used as soil manure without any adverse impact on the plants.
\end{abstract}

Keywords : Trace element, EDXRF, flyash, soil

PACS Nos. : $07.85 . \mathrm{Ne}$, 91.67.Pq, 89.60.Ec, 91.40.Bp

\section{Introduction}

The global energy needs have enormously increased with rapid increase in stress on technology and to a large extent these have been met from fossil fuels [1]. A large fraction of coal extracted from the earth is burnt in thermal power plants. Combustion of coal in the thermal power stations gives rise to gaseous and particulate pollution in the environment. In the combustion process, most of the mineral/inorganic matter in the coal is fused into ash. Roughly $20 \%$ of ash is precipitated as bottom ash or slag, and $80 \%$ as fly ash. A portion of the heavier ash, together with incompletely burnt organic matter, drops to the bottom of the furnaces as bottom ash or slag [2]. The lightest ash (fly ash) is carried away through the boiler, together with the hot flue gases and is separated from the hot gases and any volatilized mineral compounds by control devices, while the rest is released to the atmosphere. Fly ash is finally discharged either as dry powder or in the form of wet slurry. Owing mainly to the elimination of organic content of the coal, there is an enhancement of the concentration of the trace elements from coal to ash. The chemical composition of coal ash varies with coal 
quality, degree of pulverization, combustion technique and boiler operational conditions as well as mode of collection. It is recognized that health hazards and environmental impact from thermal power plants result from the mobilization of trace elements from fly ash.

In India, thermal power plants account for $65 \%$ of the installed capacity and $70 \%$ of electricity generation [3]. The share of thermal power stations is likely to reach around $75 \%$ by the year 2005 . Thermal power plants are currently using about 200 million tons of coal, which is about $60 \%$ of the total coal production. Since high-grade (low ash content) coal is reserved for metallurgical industries, railways, etc. the thermal power plants, have to utilize low grade (high ash content) coal. The ash content of Indian coal used at most thermal power plants varies from $35 \%$ to $55 \%$ and generally the average ash content is around 50\%. At present India produces around 110 million tons per annum of coal ash. Most of the ash is alkaline in nature. The generation of huge quantities of coal ash poses serious disposal and environmental problems. Coal ash has a great potential for utilization in producing building materials such as cement, concrete mix and bricks besides its agronomic value as a soil conditioner and a source of soil micro nutrients. In view of the potential of fly ash as a useful raw material, studies of elemental composition of fly ash are highly desirable.

\section{Experimental techniques}

\subsection{Sample preparation :}

For Energy Dispersive X-Ray Fluorescence (EDXRF) analysis, after crushing the samples to fine powder, $500 \mathrm{mg}$ of each of the specimens were mixed with highly pure cellulose $(99.99 \%)$ powder in $1: 1$ ratio by mass and the mixture had to be ground thoroughly to make a homogeneous mixture. Pellets of size $25-\mathrm{mm}$ diameter were obtained after putting the mixture in the $\mathrm{KBr}$ press [4].

\subsection{Data analysis :}

The EDXRF system at the Institute of Physics has been used for the analysis of fly ash samples. The spectra obtained for all the samples were evaluated using the AXIL computer program supplied by the International Atomic Energy Agency (IAEA). For both EDXRF data acquisition, a $\mathrm{Si}$ (Li) detector having an active area of $30 \mathrm{~mm}$ square was used. A 50- $\mu \mathrm{m}$ aluminized mylar was used for PIXE data acquisition for low energy suppression. Target of a certified reference material NIST Fly Ash was also prepared for analysis in the EDXRF system as standard [5].

\section{Results and conclusion}

Fourteen elements namely $\mathrm{K}, \mathrm{Ca}, \mathrm{Ti}, \mathrm{V}, \mathrm{Cr}, \mathrm{Mn}$, Fe, Co, Cu, Zn, Se, Rb, Sr and Pb have been quantified in the fly ash samples by EDXRF technique. The concentrations 
of trace elements of fly ash and soil samples are shown in Table 1. Fe was found to be present as the major element, whereas $\mathrm{K}, \mathrm{Ca}$ and $\mathrm{Ti}$ were present as minor element and they are present in percentage. Other elements like $\mathrm{V}, \mathrm{Cr}, \mathrm{Mn}, \mathrm{Co}, \mathrm{Cu}$,

Table 1. Concentration of elements (in ppm by weight unless specified) in fly ash and soil samples.

\begin{tabular}{cccccc}
\hline Elements & Angul & Farakka & Sarni & Soil 1 & Soil 2 \\
\hline $\mathrm{K}(\%)$ & 0.75 & 1.2 & 0.8 & 0.39 & 0.14 \\
$\mathrm{Ca}(\%)$ & 0.15 & 1.1 & 0.4 & 0.33 & 0.63 \\
$\mathrm{Ti}(\%)$ & 0.53 & 0.51 & 0.73 & 0.37 & 0.72 \\
$\mathrm{~V}$ & 86.3 & 102.7 & 160.2 & 354.2 & 250.0 \\
$\mathrm{Cr}$ & 96.1 & 129.1 & - & - & - \\
$\mathrm{Mn}$ & 195.4 & 238.8 & 175.2 & 611.7 & 611.7 \\
$\mathrm{Fe} \%)$ & 4.94 & 5.0 & 3.8 & 2.8 & 3.9 \\
$\mathrm{Co}$ & 21.2 & 38.1 & 23.9 & 11.2 & 28.1 \\
$\mathrm{Cu}$ & 84.4 & 79.4 & 87.6 & 109.3 & 159.7 \\
$\mathrm{Zn}$ & 62.1 & 60.4 & 39.8 & 47.0 & 55.1 \\
$\mathrm{Se}$ & 14.5 & - & 6.0 & - & - \\
$\mathrm{Rb}$ & 156.2 & 109.6 & 66.1 & - & - \\
$\mathrm{Sr}$ & 178.6 & 143.7 & 119.9 & 98.3 & 44.3 \\
$\mathrm{~Pb}$ & 21.2 & 32.9 & 39.2 & 43.3 & 7.6 \\
\hline
\end{tabular}

$\mathrm{Zn}, \mathrm{Se}, \mathrm{Rb}, \mathrm{Sr}$ and $\mathrm{Pb}$ were present in trace level. The spectrum of a fly ash sample is depicted in Figure 1. It is clear from the spectrum that the Mo X-ray peaks are present in the sample as Mo was used as the secondary fluorescer in exciting the specimen. These fly ash samples were collected from thermal power plants at Angul, Farakka, Sarni. Though the concentration of Fe was same for the samples collected from Angul and Farakka (4.94\% and 5\%), it varied a little for Sarni sample (3.8\%). Ti was highest in Farakka sample while it was same in case of Angul and Farakka

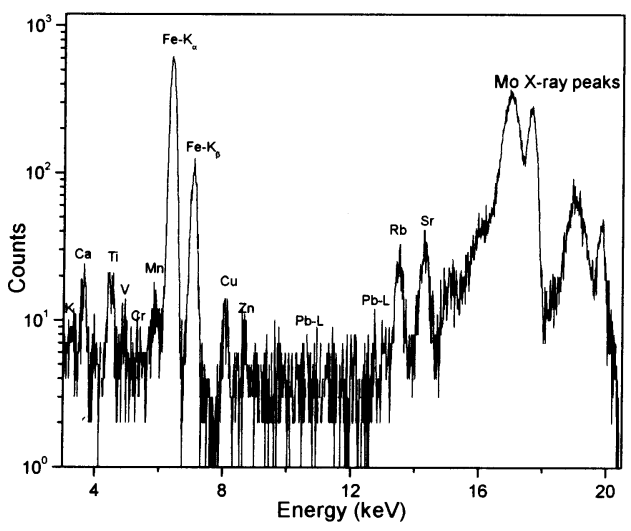

Figure 1. EDXRF spectrum of a fly ash sample of Sarni site. 
samples. Concentration of $\mathrm{Cr}$ in Farakka sample and $\mathrm{Se}$ in Sarni samples was below detection level. The variation in concentrations of trace elements in fly ash samples may be due to coals from different coal mines (sources) used at thermal power plants. Concentrations of elements in fly ash are similar with the normal soil.

Eleven elements namely $\mathrm{K}, \mathrm{Ca}, \mathrm{Ti}, \mathrm{V}, \mathrm{Mn}, \mathrm{Fe}, \mathrm{Co}, \mathrm{Cu}, \mathrm{Zn}, \mathrm{Sr}$ and $\mathrm{Pb}$ were quantified in the soil samples by EDXRF technique. The spectrum of a soil sample is depicted in Figure 2. In the soil samples also, Fe was found to be present as the major element, whereas $\mathrm{K}, \mathrm{Ca}$ and $\mathrm{Ti}$ were present as minor element and they are present in percentage. Other elements like $\mathrm{V}, \mathrm{Mn}, \mathrm{Co}, \mathrm{Cu}, \mathrm{Zn}, \mathrm{Sr}$ and $\mathrm{Pb}$ were present in trace level. In the soil samples, the element having highest concentration is $\mathrm{Fe}$, whereas $\mathrm{Pb}$ was found to possess lowest concentration. From the above study, it was found that EDXRF can effectively be used for the analysis of fly ash samples.

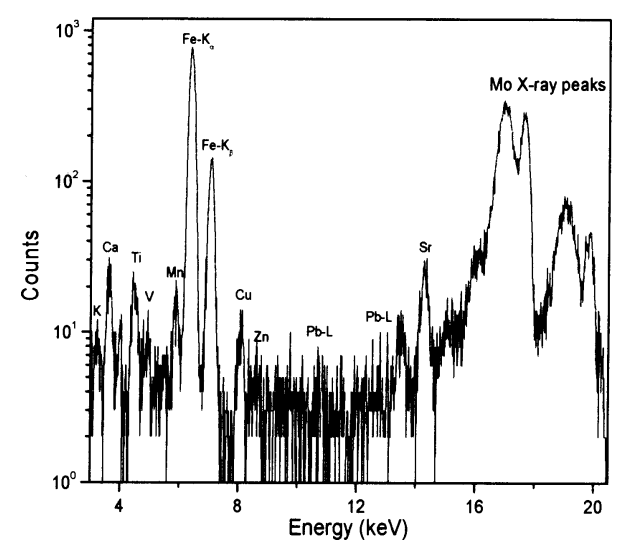

Figure 2. EDXRF spectrum of a soil sample.

\section{References}

[1] V Valvoic Trace Element Analysis (Tayler and Francis Ltd.) (1975)

[2] V S Raju, M Datta, V Seshadri, V K Aggarwal and V Kumar (eds.) Ash Ponds and Disposal Systems (New Delhi : Narosa Publ. House) (1996)

[3] V Kumar, R N Kumar and M Mathur in Proc. 3rd Int. Conf. On Fly Ash Utilisation and Disposal (New Delhi) 1 (2003)

[4] V Vijayan, T R Rautray, P K Nayak and D K Basa X-Ray Spectrom. 34128 (2005)

[5] V Vijayan, S N Behera, V S Ramamurthy, S Puri, J S Shahi and N Singh X-Ray Spectrom. 2665 (1997) 